\title{
Erratum to: Dimension of the Gibbs function topological manifold: 1. Graph representation of the thermodynamic equilibrium state
}

\section{Jan Turulski}

Published online: 1 January 2015

(C) Springer International Publishing Switzerland 2014

\section{Erratum to: J Math Chem DOI 10.1007/s10910-014-0439-5}

Unfortunately, there are some errors in Fig. 4 and Table 1 of the original publication. It has been corrected with this erratum.

The revised Fig. 4 and Table 1 are given below.

The online version of the original article can be found under doi:10.1007/s10910-014-0439-5.

\section{J. Turulski}

16-035 Czarna Wies Koscielna, Poland

\section{J. Turulski $(\bowtie)$}

Chemistry Institute, University at Bialystok, ul. Hurtowa 1, 15-399 Białystok, Poland e-mail: jan.turulski@gmail.com 


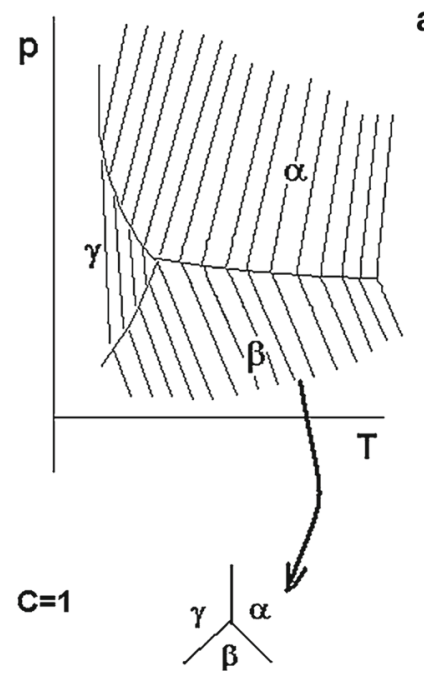

a

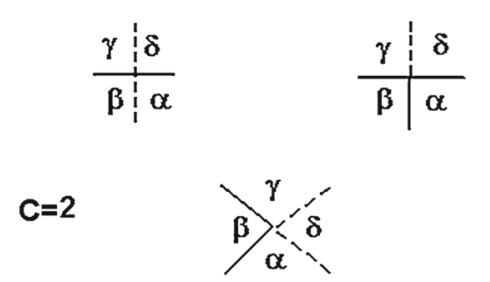

b

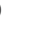

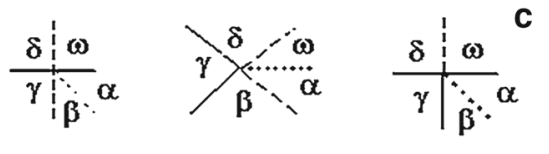

$C=3$
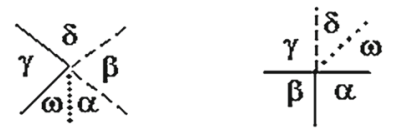

Fig. 4 Invariant state graphs for systems with $C=1,2$, and 3 independent components. Component $\mathrm{A}$ is marked with a continuous line, component $\mathrm{B}$ is marked with a dashed line, component $\mathrm{C}$ is marked with a dotted line, and component D is marked with a dashed-dotted line. Individual phases are marked with Greek letters. The composition of a given phase is marked with the lines of individual components adjacent to the phase 
Table 1 State graphs for moderately complex systems, i.e., those with $C$ no greater than 4 . The description under Fig. 4 shows individual independent components and their corresponding lines. The values of the degrees of freedom can be found in column 1 of the table. Each state graph for systems with $\mathrm{C}=4$ that will be used in the further part of this publication is marked with an identifying symbols. Description of the components and the phase is the same as in Fig. 5

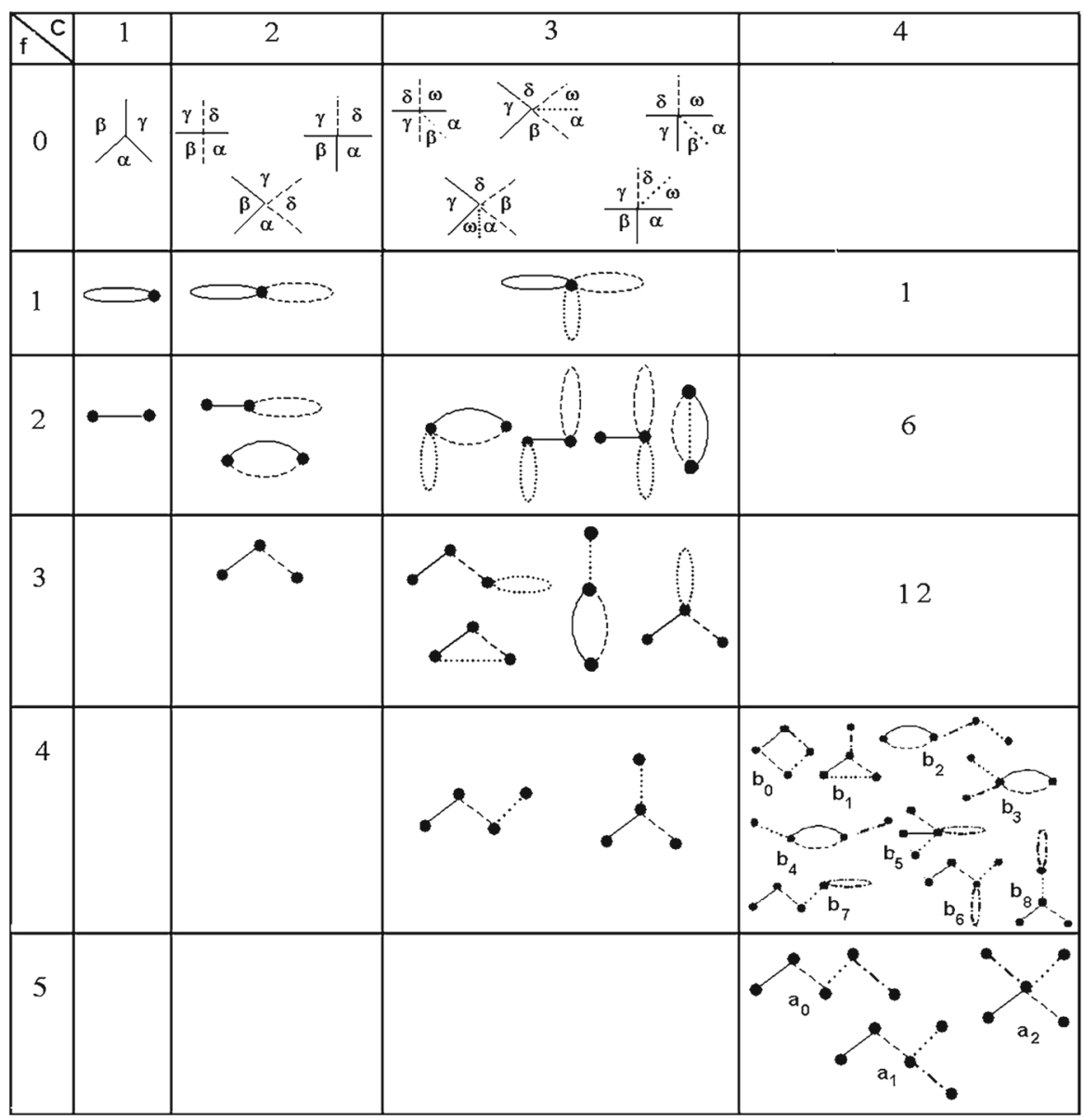

